\title{
Устойчивое развитие
}

удК 314.72

DOI: $10.17073 / 2072-1633-2017-2-162-171$

\section{Анализ пространственной мобильности населения регионов России: тенденции и механизмы}

регулирования ${ }^{1}$

\section{(C) 20172. Р.В. Фаттахов, М.М. Низамуттдинов, В.В. Орешников ${ }^{*}$}

Повышение пространственной мобильности населения на сегодняшний день является объективной составляющей социально-экономического развития во всём мире. При этом миграция выступает не только в качестве индикатора уровня жизни населения, но и в качестве фактора дальнейшего развития регионов. Сложившаяся в России ситуация характеризуется наличием большого числа регионов с негативными или нестабильными явлениями в области миграционного движения населения. Многие из этих территорий относятся к промышленно ориентированным и уже сегодня ощущают нехватку собственных трудовых ресурсов. Несмотря на меры, принимаемые в рамках действующей миграционной и региональной политики государства, указанная проблема остается актуальной.

Исходя из этого, цель исследования заключается в выявлении сложившихся тенденций в области формирования миграционных процессов в регионах РФ и разработке предложений по совершенствованию миграционной политики государства в части управления внутренними миграционными процессами. Для достижения поставленной цели был проведен статистический анализ, построенный на основе гипотезы о взаимообуславливающем влиянии социально-экономического развития региона и изменения значений показателей, характеризующих миграционные процессы. Для решения поставленных задач использованы методы структурного анализа, анализа динамики, статистического анализа и т. д.

В результате проведенного исследования осуществлена группировка регионов и сформирован комплекс предложений и практических рекомендаций, направленных на повышение эффективности государственной миграционной политики в Российской Федерации. Обоснована необходимость обеспечения единства методической и методологической базы, взаимосвязи этапов и элементов миграционной политики, применения современных информационно-коммуникационных технологий, типологизации территорий и групп мигрантов с выявлением соответствующих факторов и инструментов управления, ориентация на внутренние резервы и комплексное развитие территорий. Отмечена важность полученных результатов для обеспечения развития ключевых промышленных регионов страны.

Ключевые слова: миграционные процессы, регионы России, факторы, промышленность, управление, анализ, кластер, группировка, рекомендации

\section{Введение}

Положение экономики Российской Федерации и ее регионов в настоящее время во многом определяется уровнем развития промышленности. Рассматривая структуру валовой добавленной стоимости в стране, можно отметить, что только прямой

\footnotetext{
${ }^{1}$ Исследования проводятся при поддержке Российского фонда фундаментальных исследований.

"Фаттахов Р.В. - д-р экон. наук, професcop, fattakhov@mail.ru Финансовый университет при Правительстве Российской Федерации, 125993, Москва, Ленинградский просп., д. 49; Низамутдинов М.M. - канд. техн. наук, marsel_n@mail.ru, Орешников В.В. - канд. экон. наук, voresh@mail.ru Институт социально-экономических исследований Уфимского научного центра Российской академии наук, 450054, Уфа, просп. Октября, д. 71
}

вклад таких видов экономической деятельности как «Добыча полезных ископаемых», «Обрабатывающие производства» и «Производство и распределение электроэнергии, газа и воды» составляет более чем 23,6 \%. Однако, являясь локомотивом экономического развития, промышленность России сама в высокой степени остается зависимой от множества различных факторов, основным из которых являются трудовые ресурсы. Несмотря на автоматизацию и информатизацию процессов производства, обеспечение промышленности высококвалифицированными кадрами по-прежнему остается приоритетной задачей как отдельных предприятий, так и государства в целом $[1,2]$. При этом если на локальном уровне речь идет о поиске конкретных специалистов, то в масштабах государства на первый план выходит формирование общей демографической и, в частности, миграционной политики. В настоящее время многие районы страны сталкиваются с про- 
блемой оттока наиболее экономически активной части населения и фактически стоят перед угрозой обезлюдивания. В связи с этим, актуальными являются задачи исследования миграционных процессов на уровне субъектов Российской Федерации, выявления детерминирующих факторов и разработка мер по стабилизации и улучшению ситуации.

\section{Миграция и доля промышленности в ВРП региона}

В рамках проводимого исследования для оценки наличия взаимосвязи между показателями развития промышленности и миграционной ситуации в регионе были проанализированы соотношения таких показателей как доля видов экономической деятельности по разделам «Добыча полезных ископаемых», «Обрабатывающие производства» и «Производство и распределение электроэнергии, газа и воды» ОКВЭД в общем объеме ВРП субъекта Российской Федерации и коэффициент миграционного прироста в регионе. Принимая во внимание разноразмерность выделенных показателей, предварительно осуществлено их нормирование в соответствии с формулой (1).

$$
X_{\text {norm }}^{i}=\frac{X^{i}-X_{\min }}{X_{\max }-X_{\min }},
$$

где $X_{\text {norm }}^{i}$ - нормированное значение показателя; $X^{i}-$ текущее значение показателя; $X_{\min }$ - минимальное значение показателя в выборке; $X_{\min }$ - максимальное значение показателя в выборке, $i$ - порядковый номер региона.

Данная процедура позволила привести показатели к безразмерной форме со значением от 0 (наименьшее исходное значение в выборке) до 1 (наибольшее исходное значение в выборке).

Распределение полученных результатов по регионам представлено на рис. 1.

Построенные при этом полиномиальные линии тренда позволяют более наглядно продемонстрировать расхождение, формирующееся в крайней правой зоне графика. То есть регионы, занимающие лидирующие положения по доле промышленного производства в ВРП, характеризуются общими негативными тенденциями в части миграционных процессов. Однако, как видно на графике, значения показателей достаточно нестабильны и требуют выделения отдельных групп регионов. Для решения данной задачи по каждому из рассматриваемых показателей было выделено по 5 равных интервалов. Результаты группировки представлены в таблице.

Из представленной таблицы видно, что ни один из регионов с высокой долей промышленности в ВРП не характеризуется высокими позициями в части показателей миграции. Сложившаяся тенденция депопуляции данных территорий является прямой угрозой их дальнейшего экономического развития. Несмотря на влияние научно-технического прогресса на производственные процессы, промышленность Российской Федерации по-прежнему нуждается в высококвалифицированных кадрах. Однако проведенный анализ показал, что многие регионы страны уже столкнулись или в ближайшие годы столкнуться с проблемой нехватки трудоспособного населения, что создает дополнительные риски в данной сфере. В связи с этим представляется необходимым рассмотреть факторы, определяющие миграционное поведение населения в регионах России.

\section{Анализ факторов миграции в регионах России}

Миграционные процессы в регионах Российской Федерации происходят под влиянием множества различных причин. Основываясь на теории рационального выбора, в качестве факторов миграционного движения населения будем рассматривать характеристики отдельных территорий, в том числе описывающие экономические, социальные, экологические и иные условия жизни людей. Также следует обратить внимание, что на первый план были поставлены именно условия жизни, так как, например, условия ведения бизнеса (которые также оказывают влияние на смену места жительства отдельных

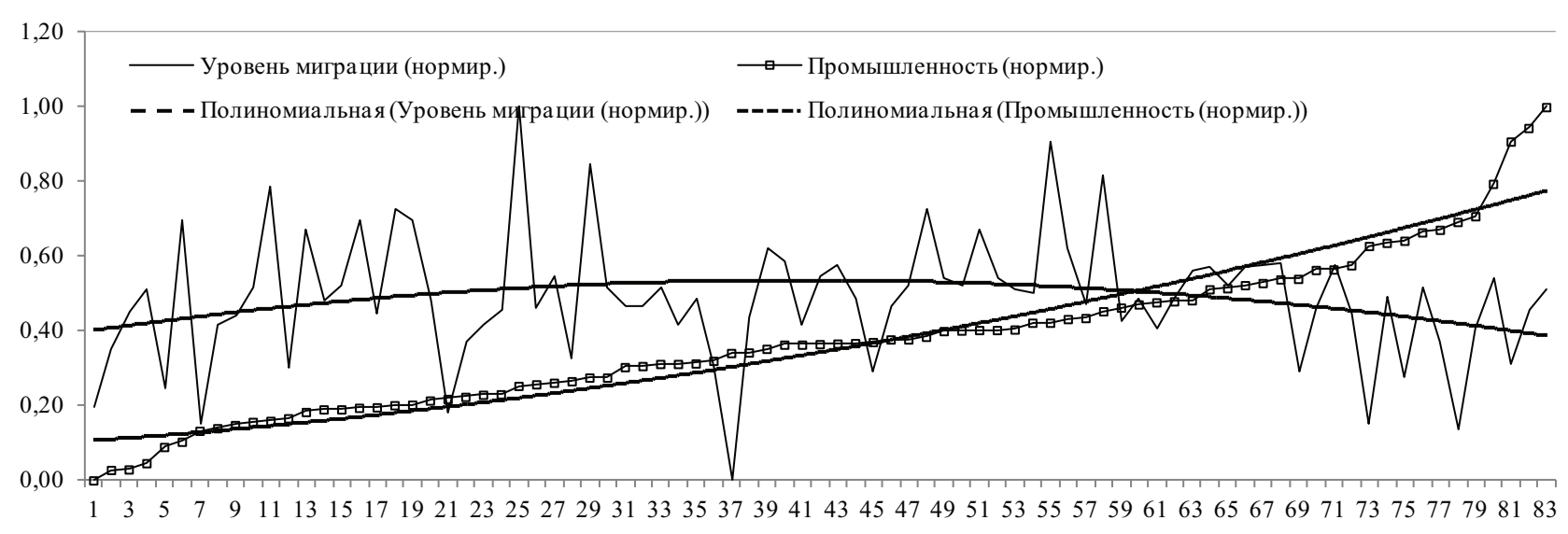

Рис. 1. Нормированные значения показателей по регионам РФ

[Normalized values of indicators by regions of the Russian Federation] 


\begin{tabular}{|c|c|c|c|c|c|}
\hline \multicolumn{6}{|c|}{$\begin{array}{c}\text { Группировка субъектов РФ (нормированные значения) } \\
\text { [Grouping of subjects of the Russian Federation (normalized values)] }\end{array}$} \\
\hline \multirow{2}{*}{$\begin{array}{c}\text { Доля промыш- } \\
\text { ленности } \\
\text { в ВРП региона }\end{array}$} & \multicolumn{5}{|c|}{ Коэффициент миграционного прироста } \\
\hline & $0,00-0,20$ & $0,21-0,40$ & $0,41-0,60$ & $0,61-0,80$ & $0,81-1,00$ \\
\hline $0,00-0,20$ & $\begin{array}{c}\text { Респ. } \\
\text { Калмыкия; } \\
\text { Еврейская АО }\end{array}$ & $\begin{array}{l}\text { Респ. Дагестан, } \\
\text { Тыва; } \\
\text { Забайкальский } \\
\text { край }\end{array}$ & $\begin{array}{c}\text { Респ. Чечня, Алтай, Северная Осетия- } \\
\text { Алания; Приморский, Ставропольский, } \\
\text { Хабаровский края; Тамбовская, } \\
\text { Орловская обл. }\end{array}$ & $\begin{array}{c}\text { Респ. Адыгея, } \\
\text { Ингушетия; } \\
\text { Краснодарский край; } \\
\text { Новосибирская, } \\
\text { Воронежская обл.; } \\
\text { г. Москва }\end{array}$ & \\
\hline $0,21-0,40$ & $\begin{array}{c}\text { Камчатский, } \\
\text { Магаданский } \\
\text { края }\end{array}$ & $\begin{array}{l}\text { Респ. Кабардино- } \\
\text { Балкария, } \\
\text { Карачаево- } \\
\text { Черкессия; } \\
\text { Курганская, } \\
\text { Мурманская обл. }\end{array}$ & $\begin{array}{c}\text { Респ. Бурятия, Мордовия, Марий Эл, } \\
\text { Чувашия, Карелия, Хакасия; Псковская, } \\
\text { Брянская, Амурская, Ростовская, } \\
\text { Пензенская, Тверская, Ивановская, } \\
\text { Астраханская, Кировская, Саратовская, } \\
\text { Смоленская, Ульяновская, Рязанская, } \\
\text { Свердловская, Нижегородская, } \\
\text { Костромская обл.; Алтайский край }\end{array}$ & $\begin{array}{c}\text { Ярославская, } \\
\text { Калининградская, } \\
\text { Белгородская обл. }\end{array}$ & $\begin{array}{l}\text { Московская обл.; } \\
\text { г. Санкт-Петербург }\end{array}$ \\
\hline $0,41-0,60$ & & $\begin{array}{l}\text { Архангельская } \\
\text { обл. }\end{array}$ & $\begin{array}{c}\text { Респ. Башкортостан, Татарстан, } \\
\text { Удмуртия; Владимирская, } \\
\text { Волгоградская, Новгородская, } \\
\text { Иркутская, Вологодская, Челябинская, } \\
\text { Омская, Тульская, Томская, Самарская, } \\
\text { Липецкая, Кемеровская обл. }\end{array}$ & Курская обл. & $\begin{array}{l}\text { Ленинградская, } \\
\text { Калужская обл. }\end{array}$ \\
\hline $0,61-0,80$ & $\begin{array}{l}\text { Респ. Коми, } \\
\text { Ямало- } \\
\text { Ненецкий АО }\end{array}$ & $\begin{array}{c}\text { Респ. Саха; } \\
\text { Оренбургская } \\
\text { обл. }\end{array}$ & $\begin{array}{l}\text { Чукотский АО; Пермский, } \\
\text { Красноярский края; Тюменская обл. }\end{array}$ & & \\
\hline $0,81-1,00$ & & Сахалинская обл. & Ханты-Мансийский, Ненецкий АО & & \\
\hline
\end{tabular}

категорий граждан, в том числе предпринимателей [3]) имеют несколько иной механизм воздействия и значимы лишь для небольшой части населения страны. На наш взгляд, множество факторов, определяющих интенсивность и направленность миграционных потоков, можно сгруппировать по следующим направлениям:

Пространственные особенности. В данном аспекте следует отметить, что восемь из десяти регионов-лидеров по величине миграционного оттока в 2014 году полностью относились к районам Крайнего Севера и местностям, приравненным к ним. Большая часть регионов полностью или частично относящихся к данным районам также относится к районам с отрицательным миграционным приростом. И только в Республике Алтай, Красноярском крае, Тюменской и Томской областях наблюдается миграционный прирост, при том, что территории данных субъектов РФ относится к районам Крайнего Севера и местностям, приравненным к ним лишь частично. Следует понимать, что освоение северных территорий имеет большое значение для промышленного развития России.

Урбанизированность территории и развитость инженерной инфраструктуры отмечается исследователями как существенный фактор миграционного поведения населения [4]. Однако при формировании межрегиональной миграции его не всегда можно считать определяющим. Так уровень урбанизованности Магаданской области составляет 95,4 \%, при этом она является лидером по миграционному оттоку населения. Значительные противоречия наблюдаются и по другим регионам.
Высокий уровень миграционного прироста наблюдается в ряде регионов, отличающихся относительно низким уровнем урбанизованности, например, Ленинградская область (64,6 \%), Краснодарский край (54,1\%), Республика Адыгея (47,1\%).

Экономическое развитие регионов, на наш взгляд, оказывает косвенное влияние, т.к. потенциальные мигранты акцентируют внимание в большей степени на уровне оплаты труда, наличии рабочих мест, доступности социальных благ, а не на динамике роста ВРП и инвестиций в основной капитал. В связи с этим промышленно развитые регионы не всегда способны удержать населения от переезда в более привлекательную часть страны [5].

Социальное обеспечение. Анализ выявил наличие взаимосвязи между рядом показателей характеризующих параметры социального развития и интенсивностью миграционных процессов. В частности, наблюдается снижение числа зарегистрированных преступлений при переходе от регионов с более сложной миграционной ситуацией к регионам более привлекательным с точки зрения переезда. В тоже время была обнаружена относительно высокая корреляция $(r=0,62)$ между обеспеченностью медицинским персоналом и коэффициентом миграции. Кроме того, одной из наиболее распространенных причин смены места жительства является именно получение высшего образования [6]. Однако в разрезе регионов выявить статистически значимую взаимосвязь между общим коэффициентом миграционного прироста населения и долей студентов высших учебных заведений не удалось. 
Труд и уровень жизни населения. Анализ доходов населения по регионам позволяет более ясно понять причины миграционных процессов. Так, Республика Калмыкия, которая выделялась по уровню ожидаемой продолжительности жизни, отличается крайне высоким уровнем бедности (34,7 \% в 2014 г.), что несомненно является фактором, определяющим ее положение среди регионов России по уровню миграционного прироста [7]. В то же время, проведенный анализ показал, что уровень оплаты труда не является единственным фактором, определяющим миграционное поведения населения, и степень его влияния не одинакова на всей территории Российской Федерации. В частности, были выделены 7 кластеров (рис. 2).

Большинство регионов (51 единица) относятся к двум кластерам, формирующим типичную картину. Первый кластер включает 25 регионов, уровень заработной платы в которых сопоставим со среднероссийским, а показатели миграционного движения населения заметно менее существенны, в большинстве случаев наблюдается относительно невысокий миграционный прирост. Для второго кластера отличительной чертой является сложная ситуация в части оплаты труда, сочетающаяся с относительно спокойной миграционной ситуацией. Третий и четвертый кластеры (в основном районы Севера) характеризуются явным несоответствием уровня оплаты труда и наблюдаемых миграционных процессов. Так, высокие заработные платы (соперничать с которыми могут только города Москва и Санкт-Петербург) не могут остановить отток населения из данных субъектов Российской Федерации. Пятый кластер является одним из наиболее проблематичных на текущий момент. Уровень оплаты труда в данных регионах сопоставим со среднероссийскими, однако миграционный отток значительно выше. В данном случае влияние оказывает и территориальная принадлежность регионов, многие из которых относятся к Северо-Кавказскому региону. Шестой кластер включает города Москва, Санкт-Петербург и «столичные регионы». Данный кластер отличают высокий уровень оплаты труда (уступает лишь первому кластеру) и положительная миграция на достаточно высоком уровне. Фактически, данный кластер «выкачивает» человеческие ресурсы с других территорий как за счет финансовых механизмов, так и за счет особого статуса. Регионы седьмого кластера являются достаточно «интересными» в том плане, что по уровню оплаты труда они зачастую уступают соседям, но при этом уровень коэффициента миграционного прироста зачастую сопоставим с показателями шестого кластера.

Демографические процессы, такие как рождаемость, коэффициент демографической нагрузки и т. д. на наш взгляд могут выступать в качестве

Дендрограмма для 83 набл. Евклидово расстояние

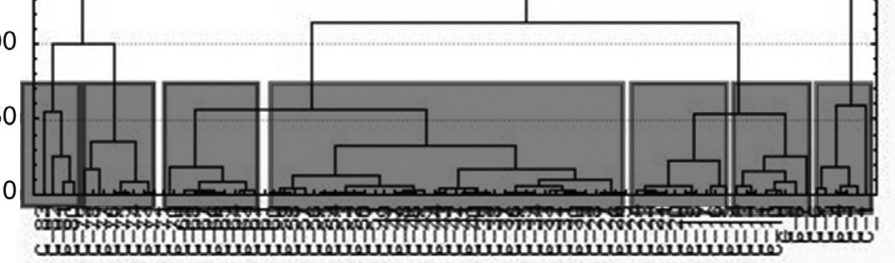

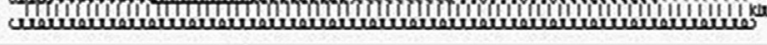

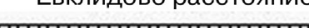


ки Российской Федерации на период до 2025 года (далее - Концепция) [10]. Именно в рамках данного документа должны быть реализованы алгоритмы управления, включающие выполнение следующей цепочки действий:

Анализ и выявление проблем;

Формирование целей и задач миграционной политики;

Прогнозирование и планирование миграционной ситуации;

Разработка проектов мероприятий в сфере миграционной политики;

Реализация разработанных мероприятий;

Мониторинг и оценка результатов реализации мероприятий.

При этом следует понимать, что данный процесс носит циклический характер, а по результатам мониторинга и оценки следует принятие соответствующих решений по корректировке как прогнозно-плановых, так и проектных параметров. Более того, возможно изменение приоритетов, то есть корректировка целей и задач миграционной политики. Это связано с тем, что миграционная политика реализуется во взаимосвязи с другими направлениями государственной политики, в том числе с целями промышленного развития регионов России. Исходя из этого, предложения по совершенствованию системы государственного управления миграционными процессами и пространственным развитием России, на наш взгляд, целесообразно сгруппировать по выделенным этапам с увязкой с вышеуказанной Концепцией.

Ключевой проблемой на всех этапах является сложность информационного обеспечения деятельности в сфере управления миграционными процессами. В связи с этим, необходимым является создание функционирующей на постоянной основе системы выявления и предупреждения проблем и кризисных ситуаций в рамках действующей системы управления на основе межведомственного взаимодействия [11]. Для реализации данного направления требуются применение современных технологий и информационных систем, позволяющих обеспечить оперативную обработку и обмен поступающей информацией (касающейся не только сугубо демографических процессов, но и отражающей развитие иных сфер общественной жизнедеятельности, в том числе потребностях промышленности регионов и городов в кадровых ресурсах). В качестве средств автоматизации административной деятельности используются разнообразные системы, обеспечивающие и координирующие совместную деятельность нескольких участников процесса управления. Основная концепция использования систем такого типа заключается в формировании единого информационного пространства, упрощении процесса обмена информацией, оптимизации работ сотрудников. Эвристическая деятельность менее всего формализуема и поэтому для её автоматизации необходима разработка и внедрение сложных систем.
В современных условиях для адекватной оценки ситуации на текущий момент и моделирования вариантов ее развития руководителю требуется переход от видения большого количества разрозненных факторов к концентрированному видению ситуации [12]. Мощным инструментом, позволяющим производить оценку возможного состояния объекта при различных изменениях факторов, является ситуационный центр.

К основным задачам функционирования ситуационного центра относятся обеспечение информационной поддержки, согласование и обеспечение целостности функционирования информационнокоммуникационных систем, сокращение временных и финансовых затрат, вызванных дублированием подготовки данных, их противоречивостью, затруднениями с доступом, выборкой и передачей информации, мониторинг состояния объекта управления, прогнозирование развития ситуации и т. д.

Интеллектуальным ядром ситуационного центра является комплекс взаимосвязанных моделей социально-экономической системы с контролируемыми параметрами, характеристиками, показателями и критериями ее оценок в соответствии с целями и задачами управления, а также алгоритмами выявления проблемных ситуаций [13], раннего предупреждения и разработки мероприятий по предупреждению и ликвидации негативных последствий кризисного развития. Учитывая необходимость выделения координирующего центра по данному направлению и формирования центров ответственности, представляется целесообразным в качестве такого органа определить Главное управление по вопросам миграции МВД России.

Направления анализа могут быть определены исходя из целей и задач миграционной политики, заложенных в Концепции, а также с учетом ее влияния на развитие промышленности в регионах. Однако следует отметить, что сама Концепция в большей части направлена на решение вопросов внешней миграционной политики, что является фактором, снижающим ее эффективность. В тоже время отмечается следующее: «Неблагоприятные тенденции наблюдаются во внутренних миграциях. Население Российской Федерации отличается более низкой территориальной мобильностью (в том числе на локальном уровне) в сравнении с другими странами. Причины обусловлены большими издержками на переселение, неразвитостью транспортной сети, ограниченностью рынка арендуемого жилья, высокой стоимостью жилья и его аренды, низкими доходами большей части населения. Основным вектором межрегиональных внутренних миграций остается движение с Востока в Центр и в Московский регион, что усиливает дисбаланс в распределении населения по территории Российской Федерации» [10]. Представляется целесообразным устранить данный недостаток за счет более полного отражения целей государства в области внутрирегиональной и межрегиональной миграции и развития экономики. 
Актуальность представленных рекомендаций подтверждается и рядом положений рассматриваемой Концепции, в которой, в частности, отмечается, что «привлечение иностранных работников по приоритетным профессионально-квалификационным группам в соответствии с потребностями российской экономики является необходимостью для ее дальнейшего поступательного развития» [10]. Однако, на наш взгляд, приоритетным является уменьшение числа случаев отъезда лиц, обладающих соответствующими качествами, за рубеж путем создания благоприятных условий, а также повышение уровня подготовки специалистов. То есть привлечение иностранных работников является необходимыми, но дополнительными мерами в данной области. Аналогичные задачи должны ставиться на региональном и муниципальном уровнях. Однако это не означает создания искусственных барьеров для снижения мобильности населения.

Оценка возможных последствий от реализации тех или иных мер, формирование и реализация государственной политики в области управления миграционными процессами требует четкого научно обоснованного представления о возможных направлениях развития изменяющейся ситуации. Актуализируются вопросы прогнозирования и планирования, которые ввиду сложности объекта управления и наличия множества пересекающихся информационных потоков также требуют применения современного инструментария. Экономикоматематическое моделирование является одним из наиболее перспективных направлений в данной сфере, позволяющим взаимоувязать ключевые факторы, рассматривать различные сценарии и оперативно получать количественные оценки последствия возможной реализации тех или иных мер. Подобная модель в совокупности с иными средствами информационно-аналитической обработки данных может стать ядром ситуационного центра и должна обладать, среди прочих, следующими характеристиками:

Представлять информацию в разрезе не только субъектов Российской Федерации, но и с учетом данных по муниципальным образованиям (в первую очередь, крупнейшим городам [14]). Таким образом может быть учтено изменение внутрирегиональных показателей, оценено влияние урбанизации, тесно связанной с развитием промышленности. В тоже время, полученные данные могут быть агрегированы с целью получения сводной информации по федеральным округам, экономическим районам или по иному признаку;

База данных модели должна быть интегрирована с другими информационными ресурсами, позволяя в автоматизированном режиме получать необходимую информацию с использованием современных информационно-коммуникационных технологий (например, сети Интернет [15]);

Возможность формирования сценариев развития ситуации за счет использования алгоритмов многовариантного прогнозирования;
Оценка устойчивости по сбалансированному набору показателей, включающих как экономические, так и социальные параметры. Данная возможность позволит получить представление о влиянии того или иного управляющего воздействия на различные сферы жизнедеятельности общества с учетом межрегиональных связей;

Учет долгосрочных последствий в рамках реализации государственной миграционной политики, а также от изменения различных внутренних и внешних параметров управляемой системы [16].

Принимая во внимание крайнюю сложность организации обновления данных в модели в автоматическом режиме, для выполнения требований оперативности представляется целесообразным минимизировать данные сроки. Для этого необходима интеграция возможностей и ресурсов информационных систем различных ведомств с разграничением полномочий и прав доступа. При этом потребуется обеспечить стабильность методик получения статистических данных. Ситуация, при которой методика расчета показателей претерпевает изменения [17] (пусть даже и с целью повышения адекватности тех или иных показателей) не позволяет применять методы статистического анализа и проводить расчетные эксперименты.

На основе полученных данных могут разрабатываться соответствующие программы и мероприятия в сфере демографии. При этом, как отмечалось ранее, следует рассматривать миграцию как элемент общего пространственного развития, соотносить с общей ситуацией по региону и по стране.

С целью формирования гибкой миграционной политики, учитывающей особенности социально-экономического развития регионов, представляется целесообразным на государственном уровне определить группы территорий, учитывающие такие характеристики как:

- географическое положение и климатические условия;

- уровень экономического развития;

- уровень жизни населения;

- уровень социального обеспечения;

- показатели безопасности [18];

- параметры демографической ситуации.

В ходе реализации данного предложения должны быть определены количественные значения для каждого региона. В данном аспекте следует отметить, что несмотря на сложности, вызываемые в большинстве случаев оттоком населения, для каждого конкретного региона, вполне возможно, что для развития страны или макрорегиона смена места жительства граждан является целесообразным явлением. В связи с этим для целей государственной миграционной политики могут быть выделены не только регионы, нуждающиеся в притоке населения, но и территории, которые могут выступить в роли «доноров». В этом случае должны быть четко определены требования к лицам, меняющим место жительства, и механизмам, позволяющим управлять 
данными процессами, т. к. бесконтрольное движение может привести к обезлюдиванию значительных территорий [19]. То есть требуется разработка перечня показателей, на которые органам государственного и муниципального управления следует ориентироваться для наиболее эффективного использования человеческого капитала регионов Российской Федерации.

Кроме того, в рамках разработки и реализации мероприятий в области государственной миграционной политики следует отметить следующие моменты, затрагивающие практические аспекты данной деятельности в Российской Федерации:

Необходимость обеспечения интеграции мигрантов в среду пребывания и недопущение создания разного рода анклавов, гетто и тому подобных образований. В связи с этим требуется анализ, в том числе, европейского опыта (как положительного, так и отрицательного).

Необходимость определения критериев и требований к потенциальным мигрантам. Подобные критерии существуют на сегодняшний день в отношении иностранной рабочей силы, но на наш взгляд, выступая в качестве ориентиров они могут быть полезны и в процессе управления внутренними миграционными потоками. Таким образом может происходить выделение специфических групп мигрантов и формирование инструментов управления актуальных для каждой группы.

Исходя из предыдущего пункта, требуется выявление факторов, воздействие на которые в наибольшей степени позволят обеспечить решение задач миграционной политики. Проведенный анализ показал, что общими для большинства мигрантов и территорий являются такие факторы, как уровень заработной платы, развития медицины и т. д. Однако, для решения более узких и специфичных задач (в том числе связанных с развитием промышленности в регионах России) требуется выявление факторов, в наибольшей степени отвечающих интересам отдельных групп населения.

Требуется разработка мероприятий по комплексному развитию территорий, для “удержания» населения. Реализуемая государственная политика по приоритетному развитию западной и центральной части страны приводит к массовому оттоку населения из других регионов. При этом точечные решения, принимаемые на федеральном уровне, не должны ограничиваться исключительно отдельными территориями Дальнего Востока или Крыма. Требуется повсеместное развитие экономики, создание производств [20], повышение конкурентоспособности, в том числе за счет роста производительности труда, создание дополнительных рабочих мест, рост доходов населения, финансирование ремонта жилья и других социальных и инфраструктурных объектов. Проведенный анализ, в частности, показал необходимость разработки совершенно особенного комплекса мер для Северного Кавказа и районов Крайнего Севера и приравненных к ним территорий.
При этом не отрицается потребность определения стратегически важных для страны регионов, в которые необходим приток мигрантов (приграничные регионы, районы Крайнего Севера и приравненные к ним местности, Сибирь, Дальний Восток).

Важным направлением остается укрепление села и повышение качества жизни в сельской местности. Для предотвращения оттока населения из деревень и их массового вымирания требуется, в первую очередь, проведение политики рурбанизации, в том числе развитие коммуникаций, повышение уровня жизни, строительство сельских и межпоселенческих дорог [21].

Требуется активная профилактика конфликтов, вызванных миграционными процессами. Несмотря на улучшение ситуации, отношение к мигрантам внутри страны остаются сложным. По результатам исследований, к приезжей семье мигрантов из Закавказья положительное отношение выразили $19 \%$, безразличное - $24 \%$, отрицательное - 53 \%; из Средней Азии - 16, 23 и 56 \%; с Северного Кавказа - 14, 20 и 60 \%, соответственно [22]. Формирование конфликтного фона особенно заметно в тех регионах, где происходит существенное изменение этнического баланса, одним из факторов которого является демографический фактор (а в ряде регионов, например, в Ставропольском крае, он является определяющим). В связи с этим, требуется регулирование внутренней миграции. Продолжение массового исхода жителей Северного Кавказа в другие регионы страны осложняет позитивные социально-экономические преобразования в республиках самого Северного Кавказа. Не нарушая конституционных прав, необходимо требовать исполнения законодательства.

В сфере внешней миграционной политики следует продолжать осуществление политики активной репатриации. Приоритетом остается привлечение в Россию соотечественников, проживающих за рубежом. Экспертами потенциал данного направления оценивается в 8 млн человек. В данном случает требуется анализ опыта других стран, в том числе Израиля, Германии, Казахстана. Следующим по приоритетности контингентом являются культурно и исторически близкие страны. Также следует учитывать такой фактор как сохранение семейных связей.

С другой стороны, следует отметить, что во внешней миграционной политике опасность вызывают не только приток жителей из стран СНГ, но и других стран востока, в частности Китая. В соседнем Китае 100-110 млн человек населения находится в приграничных с Россией северо-восточных территориях, в то время как на Дальнем Востоке проживает лишь 6,3 млн человек (5 \% населения РФ). Определенную опасность вызывает и усложнившаяся ситуация в отношениях России и Украины. По данным Всемирного Банка, миграционные направления в данном коридоре (Россия-Украина и Украина-Россия) являются вторым и третьим по масштабам антропотока, уступая лишь миграции между 
Мексикой и США. Так, на вопрос об отношении респондента к проживанию по соседству с семьей мигрантов из Украины, 48 \% опрошенных ответили положительно, 34 \% выразили безразличие и лишь 15 \% высказали отрицательное отношение [22].

Как указывалось ранее, реализация мероприятий государственной миграционной политики не является завершающим этапом данной деятельности. В рамках мониторинга и оценки результатов реализации мероприятий, на наш взгляд, целесообразным является, в том числе, обобщение полученного опыта. В частности, необходима организация постоянно действующей площадки для обмена мнениями специалистов в данной области. В данном случае также требуется использование современных информационно-коммуникационных технологий [23]. Подобная задача может решаться в рамках функционирования указанного ранее ситуационного центра. Другим направлением является проведение регулярных семинаров и конференций.

\section{Заключение}

Таким образом, следует отметить, что совершенствование системы государственного управления миграционными процессами и пространственным развитием России должно учитывать следующие моменты: базы;

- единство методической и методологической

- взаимосвязь этапов и элементов миграционной политики;

- применение современных информационнокоммуникационных технологий;

- типологизация территорий и групп мигрантов с выявлением соответствующих факторов и инструментов управления;

- ориентация на внутренние резервы и комплексное развитие территорий.

Повышение эффективности системы государственного управления миграционными процессами и пространственным развитием Российской Федерации должно носить научно обоснованный характер и строиться на основе принципов комплексности и системности.

\section{Библиографический список}

1. Industry Engagement Strategy 2020. Migration and Mobility. URL: http://www.border.gov.au/ Engagingwithindustry/Documents/ies-migration-mobility.pdf (дата обращения: 01.06.2017).

2. Nandi T.K., Kar S. Short-term Migration and Intergenerational Persistence of Industry in Rural India. URL: http://ftp.iza.org/dp9283.pdf (дата обращения: 01.06.2017).

3. Губанова Е.В., Бекчян Э.В. Особенности развития малого предпринимательства на территории Калужской области: прогнозы и перспективы //
Актуальные вопросы менеджмента современной организации. 2015. С. 25-31.

4. Abreu M., Faggian A., McCann P. Migration and inter-industry mobility of UK graduates: Effect on earnings and career satisfaction. URL: http://hdl.handle. net/10419/119917 (дата обращения: 01.06.2017).

5. Печаткин В.В., Перфилов В.А. Импортозамещающая кластерная политика как направление повышения устойчивости развития регионов России в условиях геополитической неопределенности // Региональная экономика: теория и практика. 2015. № 29(404). C. 49-58.

6. Гаврикова А.В. Демографические процессы Республики Башкортостан в контексте проблемы устойчивости территориальных образований // Современные проблемы науки и образования. 2015. № 1-2. C. 271.

7. Кабашова Е.В. Статистическое моделирование в исследовании благосостояния населения // Современные технологии управления - 2014: сборник материалов. Киров: МЦНИП, 2014. С. 356-364.

8. Фаттахов Р.В., Низамутдинов М.М. Городское расселение в России за 50 лет: оценка тенденций и перспектив // Экономика и математические методы. 2014. T. 50. № 2. C. 24-34.

9. Низамутдинов М.M., Орешников В.В. Определение параметров управления региональным развитием на основе алгоритмов нечеткой логики // Экономика и математические методы. 2016. Т. 52. № 2. C. $30-39$.

10. Концепция государственной миграционной политики Российской Федерации на период до 2025 года. URL: http://www.consultant.ru/document/cons_ doc_LAW_131046 (дата обращения: 01.06.2017).

11.Слинкова О.К., Скачков Р.А. Моделирование процесса стратегического целеполагания социально-экономического развития региона // Современные проблемы науки и образования. 2013. № 5. C. 405 .

12. Вагин С.Г. Тенденции и условия развития управления крупными социально-экономическими системами // Вестник Самарского государственного экономического университета. 2007. № 2. С. 27-30.

13. Балуев Д.Г., Новоселов А.А. Внедрение инновационных технологий в учебный процесс ФМО ННГУ: практический пример создания и использования Ситуационного центра по межнациональным конфликтам и безопасности. URL: http://www.idmedina. ru/books/school-book/?1807 (дата обращения: 22.08.2017).

14.Житкова Е.Л. Согласование интересов города и региона (опыт Краснодарского края) // Проблемы прогнозирования. 2008. № 1. С.108-122.

15. Migration and industrial relations. URL: https:// www.eurofound.europa.eu/tr/observatories/eurwork/ comparative-information/migration-and-industrial-relations (дата обращения: 01.06.2017).

16. Фролов Д.В. Разработка алгоритма влияния факторов внешней среды на региональную соци- 
ально-экономическую систему // Вестник ОГУ. 2009. № 8. С. 117-122.

17. Методологические положения по статистике. М.: Росстат, 2003. 510 с.

18. Гончаренко А.Б., Староверов О.В Мобильность населения и качество жизни // Экономика и математические методы. 2002. Т. 38. № 1. С. 24-35.

19. Фаттахов Р.В., Абдулова Л.Р., Орешников В.В. Анализ и оценка взаимовлияния параметров демографического и экономического развития регионов и городов на примере Приволжского федерального округа // Экономический анализ: теория и практика. 2016. № 2(449). С. 77-90.

20. Худякова Т.А. Диверсификация производства как способ стабилизации рыночной ситуации // Проблемы совершенствования и развития экономи- ческих отношений в переходной экономике: сборник материалов. Челябинск: ЮУрГУ, 2000. С. 329-340.

21.Дорджиева О.Б., Дорджиева Б.В., Болдырева Е.С., Басангова Н.А. и др. Управление рисками в контексте устойчивого развития сельских территорий: монография. Элиста: ЗАО НПП «Джангар», 2014. 286 с.

22. Белобородов И. Внешняя и внутренняя миграция в современной России: к вопросу о необходимости селективной политики. URL: http://www.russkie. org/index.php?module=fullitem\&id=29811 (дата обращения: 01.06.2017).

23. Baum T. Migrant workers in the international hotel industry. URL: http://www.ilo.org/wcmsp5/ groups/public/ \%40ed_dialogue/ \%40sector/documents/publication/wcms_180596.pdf (дата обращения: 01.06.2017).

Ekonomika $v$ promyshlennosti $=$ Economy in the industry

2017, vol. 10, no. 2, pp. 162-171

ISSN 2072-1633 (print)

ISSN 2413-662X (online)

\section{Russia regions' population spatial mobility analysis: trends and regulation mechanisms}

R.V.Fattakhov - fattakhov@mail.ru

Financial University under the Government of the Russian Federation, 49 Leningradsky Prospekt, Moscow 125993, Russia;

M.M. Nizamutdinov - marsel_n@mail.ru, V.V.Oreshnikov voresh@mail.ru

Institute of Social and Economic Research, Ufa Science Center, Russian Academy of Sciences, 71 Prospekt Oktyabrya, Ufa 450054, Russia

Abstract. The rise of the population's spatial mobility presents nowadays an objective ingredient of socialeconomic development in the world. The migration plays its role not only as indicator of the living standard but also of the further development of regions as well. The situation in Russia is characterized by a number of regions demonstrating negative or unstable process in migration. Many of these regions belong to industry oriented ones, and they experience the lack in manpower resources. Despite the measures taken in the frame of migration and regional politics, the problem remains acute.

The purpose of the investigation is reveling available trends in the filed of migration processes in RF regions an developing proposal to improve the migration politics. A statistical analysis was performed. The analysis rests on the assumption that the social-economic development of the region is linked with migration process indicator. To solve the task we used structural, dynamics, statistics etc. analysis methods.

As the result of the study we could separate different regions groups and to put forward practical recommendation aimed to rise the efficiency of RF state migration politics. The necessity to uniform methodical and methodological bases, to combine separate stages of migration politics, to apply modern information and communication technologies, to identify separate territories and migrants groups, to reveal corresponding management factors and instruments, to be guided by internal reserves available and be complex territory development is substantiated. It has been noted, how important are the results to secure the development of important industrial regions of the country.

Keywords: migration processes, Russian regions, industry, management, cluster, recommendations

\section{References}

1. Industry Engagement Strategy 2020. Migration and Mobility. Available at: http://www.border.gov.au/ Engagingwithindustry/Documents/ies-migrationmobility.pdf (accessed: 01.06.2017). (In Russ.)

2. Nandi T.K., Kar S. Short-term Migration and Intergenerational Persistence of Industry in Rural India. Available at: http://ftp.iza.org/dp9283.pdf (accessed: 01.06.2017).

3. Gubanova E.V., Bekchyan E.V. Peculiarities of small business development in the territory of the Kaluga region: forecasts and perspectives. Topical issues of modern management. 2015. Pp. 25-31. (In Russ.)

4. Abreu M., Faggian A., McCann P. Migration and inter-industry mobility of UK graduates: Effect on earnings and career satisfaction. Available at: http://hdl. handle.net/10419/119917 (accessed: 01.06.2017).

5. Pepachkin V.V., Perfilov V.A. An import-substituting cluster policy as a direction to increase the sustainability of the development of Russia's regions under conditions of geopolitical uncertainty. Regional economy: theory and practice. 2015. No. 29(404). Pp. 49-58. (In Russ.) 
6. Gavrikova A.V. Demographic processes of the Republic of Bashkortostan in the context of stability problems of territorial entities. Modern problems of science and education. 2015. No. 1-2. P. 271. (In Russ.)

7. Kabashova E.V. Statisticheskoye modelirovaniye v uchebnom blagosostoyaniya naseleniya [Statistical modeling in the educational welfare of the population]. Modern management technologies - 2014: Collection of Materials. Kirov: MCNIP, 2014. Pp. 356-364. (In Russ.)

8. Fattakhov R.V., Nizamutdinov M.M. Urban resettlement in Russia in 50 years: assessment of trends and prospects. Economics and mathematical methods. 2014. Vol. 50. No. 2. Pp. 24-34. (In Russ.)

9. Nizamutdinov M.M., V.V. Oreshnikov. Determination of the parameters of regional development management on the basis of fuzzy logic algorithms. Economics and mathematical methods. 2016. Vol. 52. No. 2. Pp. 30-39. (In Russ.)

10. Concept of the state migration policy of the Russian Federation for the period until 2025. Available at: http://www.consultant.ru/document/cons_doc_ LAW_131046 (accessed: 01.06.2017). (In Russ.)

11. Slinkova O.K., Skachkov R.A. Modeling the process of strategic goal-setting of social and economic development of the region. Modern problems of science and education. 2013. No. 5. P. 405. (In Russ.)

12. Vagin S.G. Tendencies and conditions for the development of the management of large socioeconomic systems. Bulletin of the Samara State Economic University. 2007. No. 2. Pp. 27-30. (In Russ.)

13. Baluev D.G., Novoselov A.A. Introduction of innovative technologies in the educational process of the FMS of the UNN: a practical example of the creation and use of the Situational Center for Interethnic Conflicts and Security. Available at: http://ww.idmedina.ru/books/ school-book/?1807 (accessed: 22.08.2017). (In Russ.)

14. Zhitkova E.L. Coordination of the interests of the city and the region (the experience of the Krasnodar Territory). Problems of forecasting. 2008. No. 1. Pp. 108122. (In Russ.)

15. Migration and industrial relations. Available at: https://www.eurofound.europa.eu/tr/observatories/ eurwork/comparative-information/migration-andindustrial-relations (accessed: 01.06.2017).
16. Frolov D.V. Development of an algorithm for the influence of the external environment on the regional socio-economic system. Bulletin of the OSU. 2009. No. 8. Pp. 117-122. (In Russ.)

17. Metodologicheskiye polozheniya po statistike [Methodological provisions on statistics]. Moscow: Rosstat, 2003. 510 p. (In Russ.)

18. Goncharenko A.B., Staroverov O.V. Mobility of population and quality of life. Economics and mathematical methods. 2002. No. 1. Pp. 24-35. (In Russ.)

19. Fattakhov R.V., Abdulova L.R., Oreshnikov V.V. Analysis and evaluation of the mutual influence of the demographic and economic development parameters of the regions and cities of the Volga Federal District. Economic Analysis: Theory and Practice. 2016. No. 2(449). Pp. 77-90. (In Russ.)

20. Khudyakova T.A. Diversifikatsiya proizvodstva kak sposob stabilizatsii rynochnoy situatsii [Diversification of production as a way of stabilizing the market situation]. Problems of improving and developing economic relations in a transitional economy: Collection of Materials. Chelyabinsk: YuUrGU, 2000. Pp. 329-340. (In Russ.)

21. Dordzhieva O.B., Dordzhieva B.V., Boldyreva E.S., Basangova N.A. and etc. Upravleniye riskami $v$ kontekste ustoychivogo razvitiya regionov [Risk management in the context of sustainable development of regions]. Elista: Dzhangar, 2014. 286 p. (In Russ.)

22. Beloborodov I. External and internal migration in modern Russia: to the question of the necessity of selective policy. Available at: http://www.russkie.org/ index. php? module=fullitem \&id=29811 (accessed: 01.06.2017). (In Russ.)

23. Baum T. Migrant workers in the international hotel industry. Available at: http://www.ilo.org/ wcmsp5/groups/public/ \%40ed_dialogue/ \%40sector/ documents/publication/wcms_180596.pdf (accessed: 01.06.2017).

Information about the authors: R.V. Fattakhov Dr. Sci. (Econ.), Professor, M.M. Nizamutdinov - Cand. Sci. (Eng.), V.V. Oreshnikov - Cand. Sci. (Econ.). 